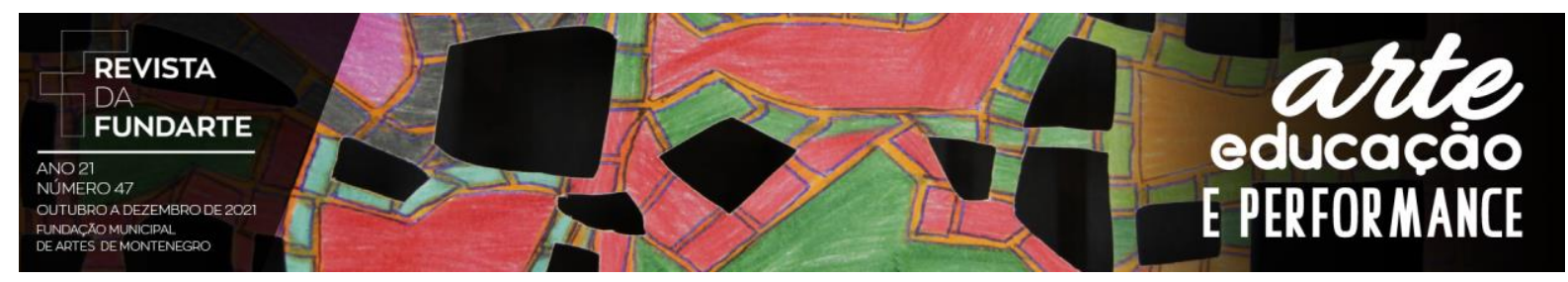

\title{
DESAFIOS DO ATENDIMENTO EDUCACIONAL ESPECIALIZADO A ESTUDANTES COM ALTAS HABILIDADES/SUPERDOTAÇÃO EM ARTES VISUAIS
}

Thérèse Hofmann Gatti Rodrigues da Costa

Fábio Travassos de Araújo

Resumo: Neste texto, buscamos analisar as políticas públicas voltadas ao atendimento educacional especializado para alunos com altas habilidades / superdotação, com foco na educação em artes visuais no contexto da educação inclusiva e da literatura especializada. Dessa forma, abordamos a legislação que reconhece esses alunos como público-alvo da educação especial, e a necessidade de formação de professores para a educação inclusiva. Defendemos a importância da formação de professores, bem como dos que atuam no ensino regular, para o reconhecimento e indicação dos alunos para atendimento, apontando a necessidade de pesquisas e investigações que observem as habilidades e comportamentos dos alunos com potencial artístico.

Palavras-chave: Ensino especial; Superdotação; Artes visuais.

\section{CHALLENGES OF SPECIALIZED EDUCATIONAL ASSISTANCE TO STUDENTS WITH HIGH ABILITIES / GIFTEDNESS IN VISUAL ARTS}

Abstract: In this text, we seek to analyze public policies aimed at specialized educational service for students with high abilities/giftedness, with a focus on visual arts education in the context of inclusive education and specialized literature. In this way, we approach the legislation that recognizes these students as a target audience for special education, and the need to train teachers for inclusive education. We argue the importance of teacher training, as well as those working in regular education, for the recognition and indication of students for assistance, pointing out the need for research and investigations that observe the abilities and behavior of students with artistic potential.

Keyword: Special education; Giftedness; Visual arts.

\section{Introdução}

Não é incomum, professores de artes identificarem diferenças de capacidades e habilidades entre os alunos de uma mesma sala de aula, quando expostos a experiências artísticas, constatando variadas aptidões no manuseio de diversos materiais que resultam em expressivas produções. Diante dessas diferenças, sempre há aqueles que se sobressaem, distinguindo-se dos demais, quanto ao nível de excepcionalidade de uma determinada atividade prática, causando admiração entre os colegas e o professor pelo nível distinto de habilidade, garantindo-Ihe, consequentemente, boa nota pelo trabalho realizado. Infelizmente, 


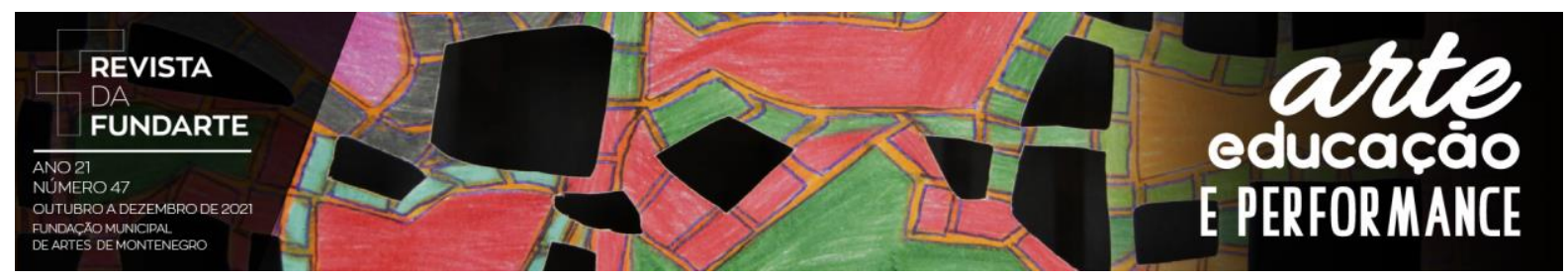

essa constatação, muitas vezes, não passa de uma simples admiração, ignorando a possibilidade de estar diante de um jovem com altas habilidades/ superdotação (AH/SD) em artes visuais.

No contexto da educação inclusiva, os alunos que constituem o público-alvo da educação especial são aqueles que apresentam deficiências, transtornos globais do desenvolvimento e AH/SD (BRASIL, 2008). Contudo, quando o assunto é educação inclusiva nas instituições educacionais, ainda causa estranheza em boa parte dos docentes quando se informa que os estudantes com AH/SD também fazem parte do público-alvo da educação especial. E, mais ainda, quando os professores de artes ficam sabendo que aqueles que demonstram potencial elevado em artes, são considerados alunos com AH/SD, com direito ao Atendimento Educacional Especializado (AEE).

Conforme a Política Nacional de Educação Especial na Perspectiva da Educação Inclusiva, os educandos com AH/SD são aqueles que:

[...] demonstram potencial elevado em qualquer uma das seguintes áreas, isoladas ou combinadas: intelectual, acadêmica, liderança, psicomotricidade e artes. Também apresentam elevada criatividade, grande envolvimento na aprendizagem e realização de tarefas em áreas de seu interesse. (BRASIL, 2008, p. 15).

Embora a definição proposta apresente uma visão geral sobre áreas de interesses e comportamentos, observados nos estudantes com AH/SD, cada indivíduo apresenta características comportamentais distintas relacionadas a sua área de desempenho, bem como comportamentos que diferem de alunos entre a mesma área e domínios de interesse distintos. Zaia e Nakano (2020, p. 32) concordam com essa discussão e complementam informando que "dada a diversidade de áreas em que a alta habilidade/superdotação pode se manifestar, bem como a possibilidade de que ela ocorra em somente uma área ou mais de uma, uma grande diversidade de traços apresentados por esses indivíduos tem sido apontada".

Certamente, esse é um dos temas mais discutidos e estudados entre aqueles que investigam esse público-alvo: a heterogeneidade demonstrada pelos diversos grupos que compõem os estudantes superdotados. Estudantes com 


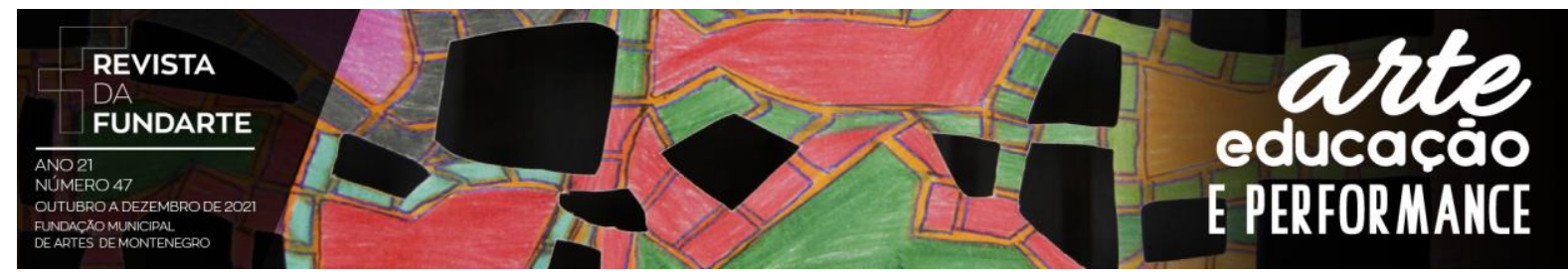

potenciais artísticos podem demonstrar variação de habilidades com mídias distintas e específicas, processos e produtos variados, interesses em domínios diferentes dentro do campo das artes, temperamentos e comportamentos que concretizam um universo complexo, heterogêneo e não fixo. Nesse sentido, Clark e Zimmerman (1992) pontuam que as afirmações dadas sobre as características dos estudantes com AH/SD em artes visuais são variadas e contraditórias, e uma definição verdadeira ou conclusiva de talentos nas artes visuais a ser utilizada para identificar esse público-alvo da educação especial não é possível, ou, talvez, até mesmo desejável.

Conquanto professores de artes enfrentam o desafio de atender a todos os alunos - sendo esses, amplamente, conhecedores da sua área de atuação, promovendo e desenvolvendo diversas experiências estéticas, artísticas e cognitivas, juntamente, com os alunos - ainda assim, os docentes podem não estar preparados para reconhecer comportamentos e habilidades artísticas específicas presentes em estudantes com AH/SD nas artes, e, em particular, nas artes visuais. Nesse sentido, a Política Nacional de Educação Especial na Perspectiva da Educação Inclusiva, (BRASIL, 2008) ao reconhecer estes estudantes e suas necessidades educacionais especiais, tem entre seus objetivos a formação de professores para o AEE e demais profissionais da educação para a inclusão, bem como a oferta do AEE aos estudantes com AH/SD, inclusive com potenciais artísticos.

Diante do exposto, por entender que o professor de artes visuais na educação regular de ensino - a partir de suas práticas pedagógicas - se encontra em uma posição-chave (VIRGOLIM, 2019) para a indicação e encaminhamento de estudantes com AH/SD em artes visuais ao apoio especializado em uma sala de recursos, este texto abordará a importância de políticas públicas na formação de professores de artes para a educação inclusiva, com foco na inclusão dos alunos com AH/SD em artes visuais, bem como a literatura que sustenta o conhecimento sobre essa população específica, advogando em relação a necessidade de pesquisas, formação de professores e o reconhecimento desse público como uma 


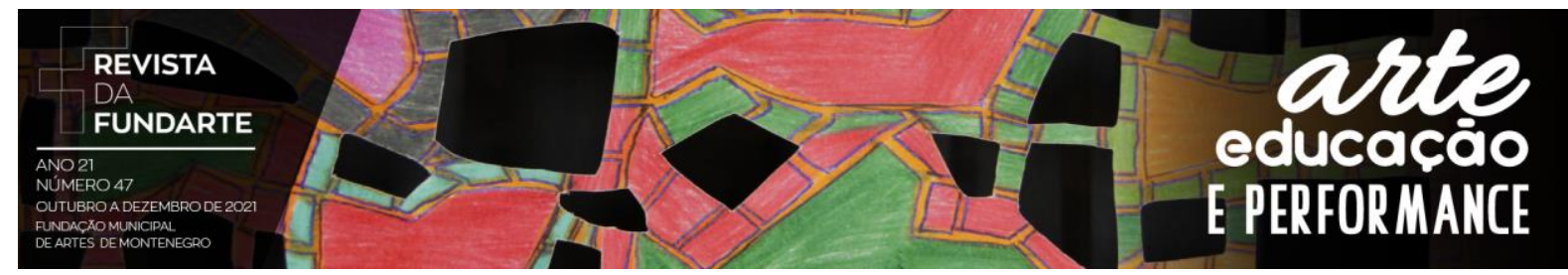

população que carece de uma educação especializada, a qual atenda às suas necessidades educacionais que emergem de suas potencialidades artísticas.

\section{Adequações legais para um indivíduo ainda invisível}

A Política Nacional de Educação Especial na Perspectiva da Educação Inclusiva (BRASIL, 2008) apresentava um conjunto de orientações políticopedagógico que visava superar a fragmentação do ensino para os alunos da educação especial, e romper com a lógica da exclusão e da homogeneização. Dessa forma, tais orientações foram direcionadas para subsidiar os processos de escolarização de maneira que contemplassem transversalmente todos os níveis, etapas e modalidades de ensino.

Além de incorporar profundas mudanças, principalmente no que se refere a troca de paradigma da integração para a de inclusão da Educação Especial na Educação Básica, referido documento também reconheceu os estudantes com $\mathrm{AH} / \mathrm{SD}$ por suas necessidades especiais, que, entre outras garantias, assegurava a esses estudantes o acesso ao ensino regular com oferta do AEE e professores com formação adequada para atender as necessidades desses estudantes. Tais considerações, pautadas no texto do documento, sugerem ações pedagógicas para a promoção do conhecimento sobre a existência dessa população escolar específica, com vistas a fornecer subsídios para a efetivação de uma identificação adequada por parte dos profissionais de educação, a fim de viabilizar um atendimento que responda às necessidades educacionais dessa população da educação especial.

Com o foco no AEE de qualidade, o documento condiciona a atuação do professor na educação especial, mediante formação inicial e continuada, tanto nos conhecimentos gerais para o exercício da docência quanto em conhecimentos específicos da área. Nessa perspectiva, esse professor especialista tem a capacidade de atuar no AEE e articular o trabalho pedagógico com o ensino regular de forma que identifique, elabore e organize "recursos pedagógicos e de 


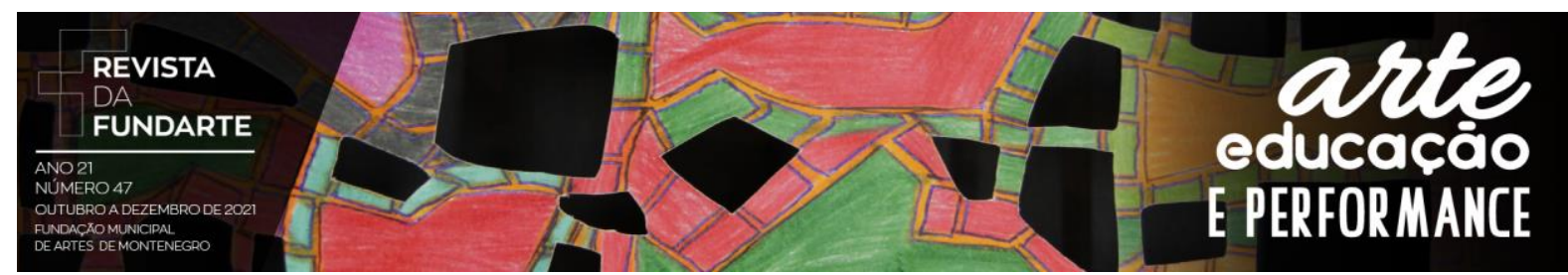

acessibilidade que eliminem as barreiras para a plena participação dos alunos, considerando as suas necessidades específicas" (BRASIL, 2008, p. 16).

Ainda de acordo com as orientações do documento, as atividades desenvolvidas na sala de aula comum não deveriam se estender ao AEE como forma de "reforço" nem este deveria ser substitutivo da escolarização. Ambas, educação comum e educação especial, deveriam manter-se em permanente diálogo e articulação em favor do desenvolvimento do estudante com AH/SD. Sendo assim, é necessária a articulação entre a educação comum e a educação especial de forma que certas condições importantes ao desenvolvimento integral dos estudantes com AH/SD sejam promovidas nessa articulação, a fim de possibilitar aos alunos o avanço em direção às suas áreas de interesse.

Em 2009, por conseguinte, um ano após a divulgação da Política Nacional de Educação Especial na Perspectiva da Educação Inclusiva, é que a Resolução no 4 do Conselho Nacional de Educação institui diretrizes operacionais para o AEE da educação básica, contemplando na legislação as orientações elaboradas pelos pesquisadores renomados que faziam parte do Grupo de Trabalho, ao prever para os estudantes com AH/SD a matrícula em classes comuns de ensino e no contraturno. A legislação indica possíveis locais que, esse atendimento, pode ser ofertado, tais como: salas de recursos multifuncionais; centros de AEE da rede público; instituições comunitárias, confessionais ou filantrópicas sem fins lucrativos; núcleos de atividades para as AH/SD, bem como as instituições de ensino superior e institutos voltados ao desenvolvimento e promoção da pesquisa, das artes e dos esportes (BRASIL, 2009).

Como ressalta Delou (2018), há a previsão de que o AEE ocorra de forma mais ampla, tanto dentro do próprio ambiente escolar do aluno, com pares da mesma idade ou entre alunos mais velhos; bem como extramuros em institutos que desenvolvam e promovam pesquisas, artes e esportes ou instituições de ensino superior em contato com estudantes universitários, com formação dentro de áreas de interesses comuns ou diferenciadas; mas sempre em articulação com o sistema de ensino regular. 


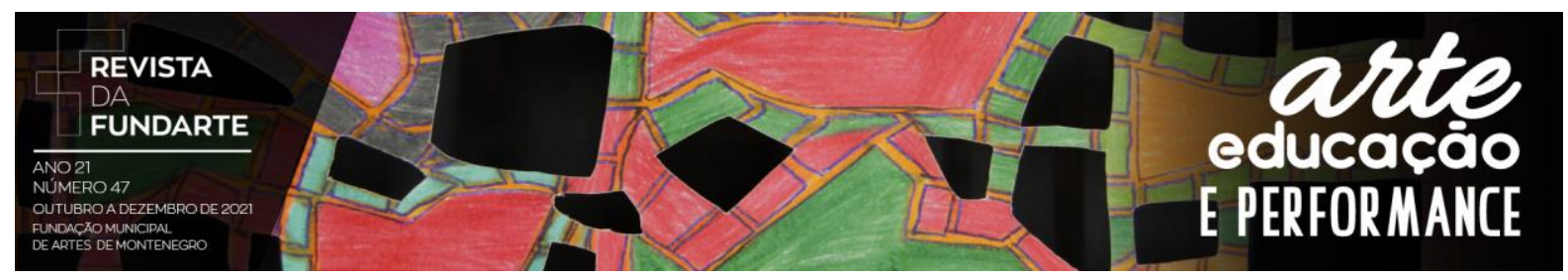

Posteriormente em 2011, o Decreto 7.611, de 17 de novembro, que substituiu o decreto $6.571 / 2008$, definiu o tipo de trabalho a ser desenvolvido com os alunos AH/SD, sendo de caráter suplementar e focando no enriquecimento de conteúdos que sejam adequados às suas necessidades, direcionadas a suas potencialidades; e que atendam aos seus interesses e áreas de destaque. Nesse sentido, as atividades desenvolvidas - com/para estes alunos - devem fornecer uma "variedade de experiências de aprendizagem enriquecedoras que estimulem o potencial dos alunos, as quais normalmente não são apresentadas no currículo regular" (VIRGOLIM, 2019, p. 153).

Embora algumas alterações na redação da Lei de Diretrizes e Bases da Educação Nacional (LDBEN) n॰ 9.394/1996 (BRASIL, 1996) tenham sido realizadas nos últimos anos, com a finalidade de se adequar às prerrogativas da Política Nacional de Educação Especial na Perspectiva da Educação Inclusiva, atendendo a todo público-alvo da educação especial, cabe destacar a inclusão da Lei ํㅡ 13.234, de 2015, a qual contempla exclusivamente os estudantes com AH/SD, estabelecendo que:

Art. 1 ㅇEsta Lei dispõe sobre a identificação, o cadastramento e o atendimento, na educação básica e na educação superior, de alunos com altas habilidades ou superdotação.

Art. 2 으 Lei no 9.394, de 20 de dezembro de 1996 (Lei de Diretrizes e Bases da Educação Nacional), passa a vigorar com as seguintes alterações:

Art. $90 \ldots . . . .$.

IV-A = estabelecer, em colaboração com os Estados, o Distrito Federal e os Municípios, diretrizes e procedimentos para identificação, cadastramento e atendimento, na educação básica e na educação superior, de alunos com altas habilidades ou superdotação;

(NR) (BRASIL, 2015)

A referida lei reforça a necessidade de se buscar meios e formas de identificação desse público-alvo da educação especial, tanto na educação básica quanto na educação superior, evidenciando a importância da aquisição do conhecimento, em âmbito nacional, sobre essa parcela da população que necessita de um suporte educacional específico e especializado nas redes públicas de ensino. Diante disso, se estabelece a implementação de procedimentos e estratégias de atendimento com diretrizes educacionais adequadas às especificidades desses 


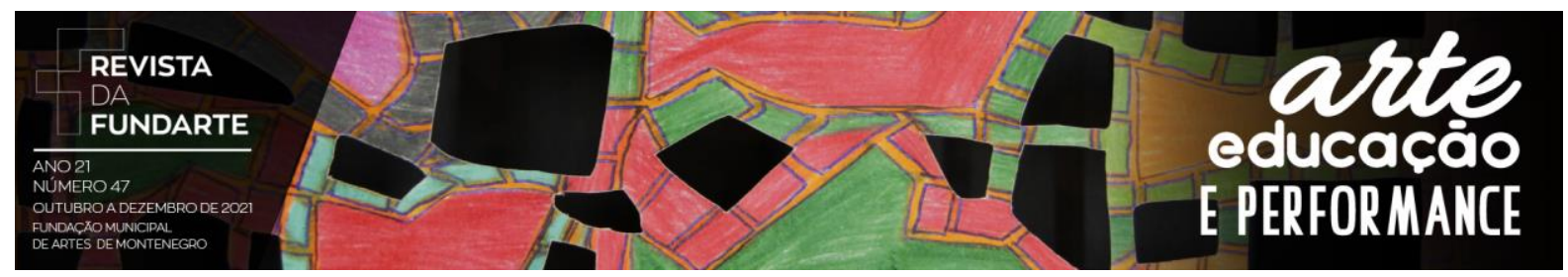

estudantes, assim como o cadastramento nacional. Esse último é estabelecido na alteração do artigo 59-A da mesma lei com a seguinte redação:

Art. 59-A. O poder público deverá instituir cadastro nacional de alunos com altas habilidades ou superdotação matriculados na educação básica e na educação superior, a fim de fomentar a execução de políticas públicas destinadas ao desenvolvimento pleno das potencialidades desse alunado.

Parágrafo único. A identificação precoce de alunos com altas habilidades ou superdotação, os critérios e procedimentos para inclusão no cadastro referido no caput deste artigo, as entidades responsáveis pelo cadastramento, os mecanismos de acesso aos dados do cadastro e as políticas de desenvolvimento das potencialidades do alunado de que trata o caput serão definidos em regulamento. (BRASIL, 1996, p. 40).

Ressalta-se que a ideia desse cadastro nacional foi proposta pelo então senador Marcelo Crivella, por meio do Projeto de Lei do Senado (PLS) ‥ - 254/2011, que apresentou no texto original da proposta uma série de justificativas, destacando argumentos que presentifica a urgência e a necessidade da alteração da lei, constatando que:

O Brasil carece de uma política de estímulo às pessoas com altas habilidades e superdotadas, desperdiçando muitos talentos que poderiam contribuir, de maneira significativa, para o desenvolvimento nacional.

Um dos maiores gargalos nessa área diz respeito às dificuldades do sistema educacional para identificar os alunos superdotados ou talentosos, proporcionando-Ihes serviços pedagógicos suplementares e especializados, que os motivem a permanecer na escola e a desenvolver plenamente suas habilidades de destaque. (BRASIL, 2011b, p. 02.).

Uma das barreiras de maior dificuldade em se transpor, a qual antecede a identificação, o cadastramento e o atendimento de alunos com AH/SD em espaços adequados que proporcionem esses processos, ocorre no momento de reconhecer comportamentos e habilidades os quais possibilitem a indicação ao AEE. Nessa lógica, é fundamental que haja "professores com especialização adequada em nível médio ou superior, para atendimento especializado, bem como professores do ensino regular capacitados para a integração desses educandos nas classes comuns" (BRASIL, 1996, p. 40).

Entre os diversos agentes envolvidos - professores, pais, profissionais de educação, amigos ou até o próprio aluno - no procedimento de indicação ao AEE, 


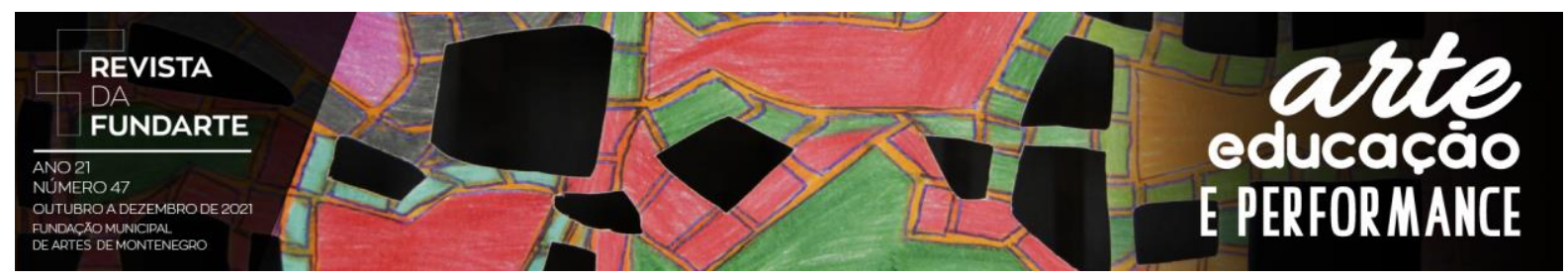

são os professores no contexto da educação regular aqueles que deveriam, a priori, estar mais capacitados em reconhecer potenciais notáveis dos seus alunos. Isso porque são nas diversas atividades, conteúdo e/ou experiências vivenciadas em sala de aula que os alunos vão deixando pistas sobre seu alto potencial ao demonstrar domínio em áreas específicas de conhecimento da atuação do professor. Virgolim (2019) aponta o importante papel do professor diante do reconhecimento das características de AH/SD, encontrando-se este em uma posição-chave quanto a indicação daqueles alunos que não são facilmente detectados em testes padronizados.

No entanto, parece que há problemas quanto à eficácia dessa indicação, já que, ainda há certa limitação por falta de formação e capacitação adequada para o reconhecimento de características comportamentais que distinguem esses alunos em relação aos demais em sua sala de aula. Pelo menos é isso que entendemos quando Almeida e Miguel (2020) denunciam que:

[...] muitos professores têm dificuldades em identificar as altas habilidades/ superdotação, talvez por não obtiverem o conhecimento teórico necessários sobre as altas habilidades/superdotação, desta forma passam a fazer ideias errôneas sobre estes alunos ou mesmo pelo próprio ego, de que o professor é o detentor do saber, e seus aluno devem apenas receber aquelas informações de forma sistêmica sem que o aluno possa expressar seus anseios e questionamentos dos assuntos que o professor aborda, ou saber sobre determinados tema mais que o professor.(ALMEIDA; MIGUEL, 2020, p. 925).

Nakano (2020) reforça nossa suspeita de que a indicação dos estudantes com AH/SD ainda é limitada dado o contexto da subnotificação desse público no Censo Escolar de 2016 em relação ao que preconiza a Organização Mundial de Saúde (OMS). Dessa forma, a autora em tela esclarece que "parte dessa situação pode ser compreendida perante a dificuldade que ainda persiste na identificação desses alunos a qual, consequentemente, tem impedido seu registro no censo escolar e oferecimento de atendimento adequado às necessidades educacionais dessa parcela de estudantes" (NAKANO, 2020, p. 71).

Essa dificuldade, segundo seu entendimento, parte de questões bem demarcadas, tais como: (1) dificuldades dos professores em identificar o potencial 


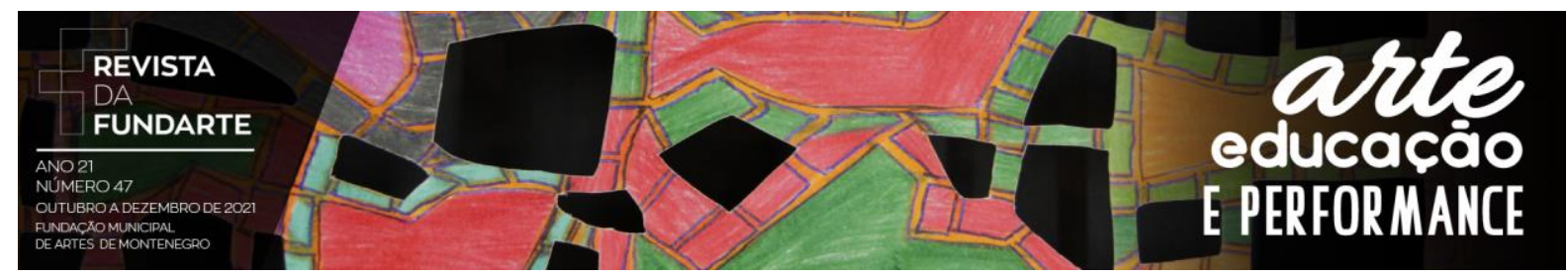

dos alunos, (2) despreparo desses profissionais durante seu processo de formação, (3) compreensão ainda restrita do fenômeno como manifestação exclusiva de alta inteligência, bem como (4) a presença de uma série de mitos no senso comum (NAKANO, 2020).

Por outro lado, quando o professor de uma disciplina específica é sensível as potencialidades dos seus alunos, conseguindo reconhecer potenciais notáveis no(s) domínio(s) relacionados a sua disciplina, possivelmente, a indicação ao AEE, e a posterior identificação no âmbito do ensino especial, terá sucesso na efetivação do atendimento e do cadastramento desse estudante. Portanto, defendemos que o professor do ensino regular habilitado para o exercício da docência em área de conhecimento específico, com formação específica em educação inclusiva e conhecimento na área das altas habilidades/superdotação, atento ao reconhecimento das potencialidades dos estudantes, é uma "peça-fundamental" para a indicação desses estudantes em áreas de conhecimento específico.

Todavia, não bastam "boas intenções" ou "a pura sensibilidade do professor" para que seja efetivada a indicação e inclusão dos estudantes com AH/SD, é necessário a concentração forças na

[...] formação dos professores, desde sua formação inicial, assim como na formação continuada aos professores em exercício docente, para que se apropriem de conhecimentos adequados sobre o tema, desvinculando-se de mitos e representações equivocadas sobre 0 assunto das altas habilidades/superdotação, para realizar assim os encaminhamentos necessários junto ao profissional da educação especial. (RECH; NEGRINI, 2019, p. 497).

Diante de diversas questões, que impedem todo o processo de identificação, cadastramento e atendimento desse público específico da educação especial, 0 Projeto de Lei do Senado (PLS) n. 254/2011 finaliza em sua redação, dizendo que:

[...] para assegurar a identificação precoce dos alunos com altas habilidades/superdotação, de modo a incluí-los o mais cedo possível no cadastro nacional e nas políticas de apoio e fomento a suas potencialidades, sejam promovidas amplas iniciativas de formação inicial e capacitação em serviço para os profissionais da educação pública. Só assim será possível dar materialidade ao cadastro ensejado e mobilizar a sociedade para a importância de lapidar talentos acima da média e, assim, 


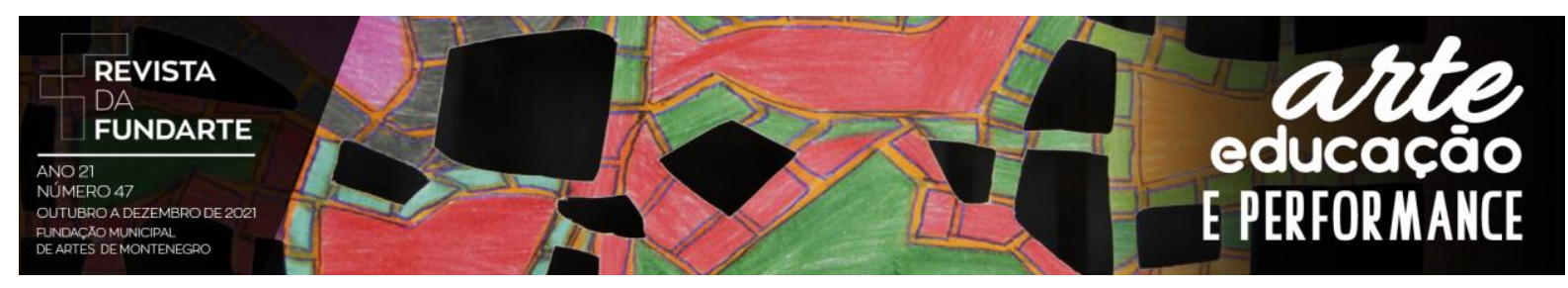

transformar promessas e potenciais em realizações e feitos extraordinários para o País. (BRASIL, 2011b, p. 03-04).

Tendo em vista as evidências constatadas por Sarki e Camargo (2019) de que muito embora as propostas de formação em Educação Especial sejam importantes, há lacunas quanto a temática das AH/SD diante da formação inicial e continuada dos professores, verificada como uma temática de visibilidade restrita nos espaços de formação que tratam da Educação Especial. Dessa forma, elas reforçam suas evidências, levantando um corpo de pesquisas que constatam que o fraco aprofundamento dos estudos sobre o tema na Educação Especial, bem como sua inserção nos cursos de formação inicial e/ou continuada, reside no povoamento de mitos e crenças populares, ou pior, a naturalização da inexistência desse públicoalvo.

\section{Reconhecendo potenciais em sala de aula regular}

Como pontua Pérez (2018), a legislação educacional brasileira no que se refere às $\mathrm{AH} / \mathrm{SD}$ é completamente problemática, posto que tenha avançado nas últimas décadas. Isso porque, segundo ela, são poucos os dispositivos legais que compreendem os estudantes com AH/SD em sua totalidade e especificidade, bem como não assimilam de forma adequada às necessidades educacionais especiais desse público-alvo da educação especial. Nesse sentido, como resultado dessa incompreensão, observa-se dificuldades quando se trata do reconhecimento desses estudantes no contexto escolar.

Conquanto, muitos estudantes com AH/SD não enfrentam obstáculos em relação ao acesso à educação básica, o mesmo não ocorre em relação à educação especial. A falta de conhecimento sobre a existência desses estudantes no contexto de sala de aula regular os colocam em volta de um campo de invisibilidade, passando despercebidos por toda sua trajetória educacional.

De certa forma, essa desatenção dos professores pode até ser intencional, já que muitas vezes esses alunos podem "gerar problemas", quando suas necessidades demandam um trabalho diferenciado por parte desse professor. Nesse 


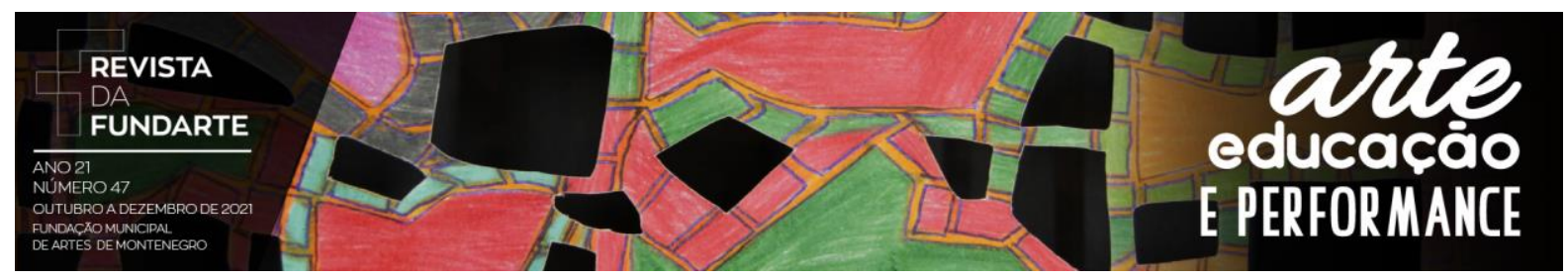

sentido, Marques e Costa (2018) pontuam que existe muita relutância nas escolas, e também em alguns professores, isso porque, ao demonstrar potenciais notáveis na realização de procedimentos e objetivos escolares, que evidenciam suas capacidades acima da média, a escola (professor), muitas vezes, resiste em garantir seus direitos. Essas autoras são categóricas quando afirmam que

\begin{abstract}
É preciso que o sistema educacional [professores] tenha conhecimento de que uma Educação voltada apenas para o(a) estudante que se posiciona na média e abaixo da média pode significar o não reconhecimento e o desestímulo do talento daqueles(as) mais capazes e, consequentemente, o não aproveitamento de suas habilidades, evidenciando-se a omissão da premissa de que a educação é um direito de todos(as). (MARQUES; COSTA, 2018, p. 7-8, grifo nosso).
\end{abstract}

Não é incomum ocorrências em escolas regulares de alunos com AH/SD relatadas por alguns poucos professores. No entanto, pela falta de formação sobre comportamentos e habilidades desse público da educação especial, essa percepção inicial não passa de espanto ou admiração diante dos potenciais dos estudantes; ora com certo ar de desconfiança; ora com ideias equivocadas sobre seus potenciais, reforçando mitos que dificultam a compreensão sobre as reais necessidades desses estudantes. Como constata Pereira (2018), há uma grande lacuna na formação dos professores a qual dificulta a oferta de um atendimento específico que responda às expectativas dos alunos com AH/SD. Segundo a pesquisadora, os problemas são variados, desde um olhar mitificado acerca da conceituação e caracterização desses alunos até a dificuldade de mapear as habilidades específicas e áreas fortes de desempenho. Aspectos, estes, que podem contribuir em estratégias educacionais para $\mathrm{o}$ atendimento às necessidades dessa população.

Em um cenário educacional - no qual o currículo é comum para todos os jovens sem ao menos considerar suas afinidades, interesses e talentos em áreas específicas de conhecimento, agravado por uma perspectiva de "déficit" que coloca em evidência os pontos fracos do aprendizado dos jovens em detrimento dos aspectos mais fortes, muitas crianças e adolescentes com AH/SD passam despercebidos no contexto de sala de aula. Pereira (2018) coloca que há um grande 


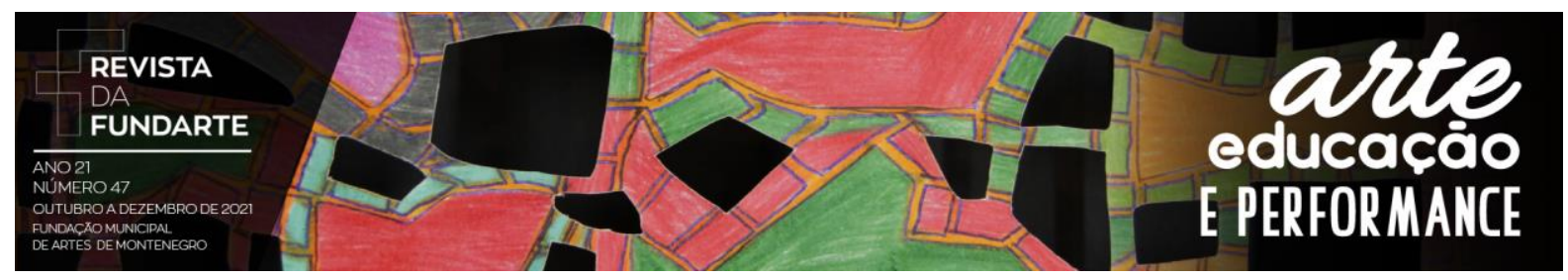

desconhecimento das estratégias educacionais contidas nos vários documentos oficiais que normatizam as ações educativas para os estudantes com AH/SD.

A falta de conhecimento específico sobre esse estudante-alvo no contexto da educação regular compromete 0 reconhecimento dos seus potenciais, impossibilitando práticas pedagógicas que contemplem suas necessidades educacionais, bem como inviabilizando a indicação e o encaminhamento ao AEE para a realização de procedimentos de identificação e enriquecimento escolar. Nesse sentido, Pérez (2018) constata que:

Como os docentes não recebem formação para identificar os alunos com $\mathrm{AH} / \mathrm{SD}$ e nem para oferecer o $\mathrm{AEE}$, os professores de sala comum não encaminham esses estudantes para as salas de recursos multifuncionais e os professores que atuam nelas, principais responsáveis pela identificação e atendimento educacional especializado, quando recebem algum caso isolado, não se sentem capacitados e se recusam a atendê-los. (PÉREZ, 2018, p. 322).

Observa-se que a indicação realizada pelo professor de sala de aula do ensino regular é fundamental para a efetivação da identificação dos potenciais e posterior desenvolvimento desses estudantes. Motivo pelo qual, quando o professor se encontra preparado e treinado para essa identificação inicial, podem fornecer informações substanciais aos procedimentos de identificação e estratégias pedagógicas para o $A E E$, bem como pode proporcionar ao professor do $A E E$ condições de estabelecer articulação junto ao seu trabalho, promovendo a participação integral dos alunos nas atividades escolares. Nesse sentido, para que a inclusão seja efetivada com o atendimento amplo e adequado aos estudantes com $\mathrm{AH} / \mathrm{SD}$, é imprescindível que se estabeleçam parcerias entre professor especialista e o professor do ensino comum, ambos trabalhando em conjunto (RECH; NEGRINI, 2019).

\section{Reconhecendo potenciais artísticos na aula de artes}

O reconhecimento dos potenciais notáveis dos alunos perpassa por dinâmicas complexas que devem ser gerenciadas já em sala de aula regular, e 


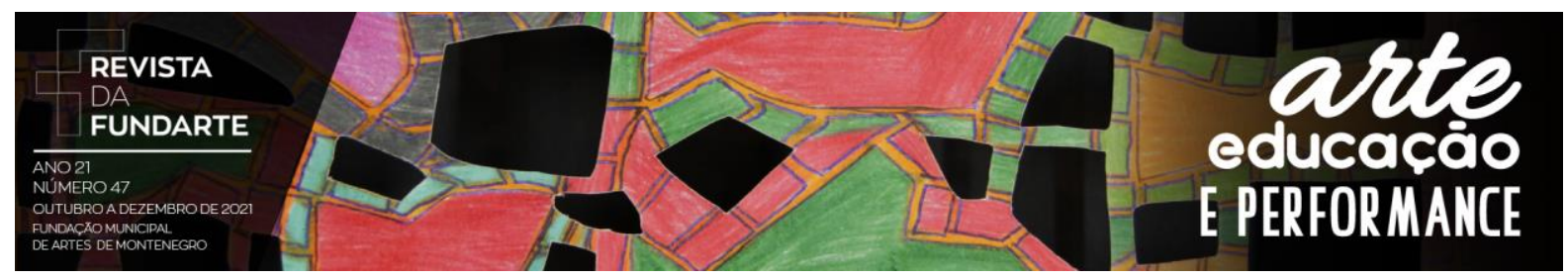

percebidas em domínios e contextos específicos. Para tanto, o professor do ensino regular necessita ser orientado quanto às diversas formas de identificar comportamentos e habilidades que caracterizam esse público-alvo da educação especial. Ser capaz de perceber os pontos fortes dos estudantes; entendendo como provável potencial notável que possa sinalizar como um indivíduo com AH/SD; talvez, seja o primeiro passo para valorizar o desenvolvimento de habilidades e competências em áreas de interesse, facilitar modos de uso no domínio do talento, e observar como o desempenho reflete excelência em sua área de destaque. Nesse sentido, Guenther (2012) esclarece que:

Reconhecer capacidade em uma criança começa por perceber algumas áreas em que ela se sai bem: boas ideias, boa produção, comentários interessantes e oportunos, observação detalhada, conclusões seguras, produção concreta em alguma tarefa. Em qualquer situação, o foco é no que o aluno consistentemente faz bem, melhor do que a grande maioria dos pares da mesma idade e mesmo tipo de experiência de vida. (GUENTHER, 2012, p. 65).

Como bem explica Virgolim (2019, p. 108) "as pessoas superdotadas diferem amplamente entre si em relação aos seus interesses, estilos de aprendizagem, níveis de motivação e de autoconceito, características de personalidade e, principalmente, por suas necessidades educacionais". Diante do exposto, cabe ressaltar que as AH/SD por ser um conceito multifacetado inclui uma diversidade de talentos (SIGNORINI; RONDINI, 2021).

Portanto, é necessário reconhecer que estudantes com AH/SD, com potenciais notáveis em áreas distintas das acadêmicas, como as artes visuais, necessitam de profissionais preparados para reconhecer os potenciais artísticos desses estudantes; seja a partir das experiências estéticas, artísticas e cognitivas promovidas em sala de aula, seja pelas experimentações artísticas vivenciadas nos extramuros que circulam no ambiente escolar, com o objetivo de atender suas necessidades educacionais artísticas no contexto de sala de aula; bem como indicar - quando necessário - para um AEE que possa nutrir, potencializar e enriquecer sua área de interesse. 


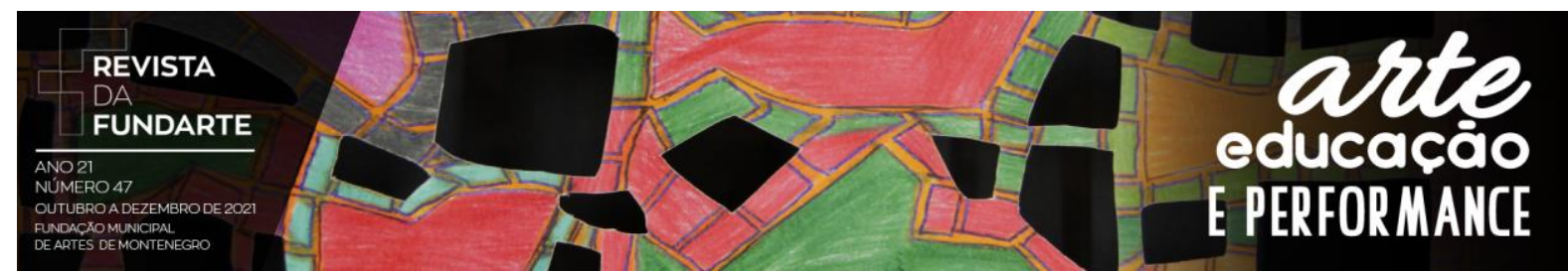

A definição de AH/SD descrita na Política Nacional de Educação Especial na Perspectiva da Educação Inclusiva (BRASIL, 2008) evidencia as artes como área potencial do surgimento desse estudante-alvo, que, desse modo, coloca em destaque as linguagens como as artes visuais, a dança, a música e o teatro, constituintes do componente curricular do ensino da arte na educação básica (BRASIL, 1996). Nessa acepção, Cuchi e Pérez (2020) sinalizam que na identificação de grupos distintos de talentos, há a necessidade de metodologias diversas, utilizando-se de critérios específicos apropriado para cada área, em outras palavras, para reconhecer talentos artísticos, há que se considerar comportamentos observáveis e habilidades artísticas específicas que emergem de cada linguagem artística.

Clark e Zimmerman (2004), ao pesquisarem estudantes com AH/SD em artes visuais, sustentam a ideia de que estes estudantes são uma população única de pesquisa, e que não são estudados com profundidade em investigações do mesmo modo que são estudados os estudantes com AH/SD em áreas acadêmicas. Os pesquisadores pontuam, ainda, que os educadores que trabalham com esses alunos precisam entender as diferenças que essa população tem dos demais alunos "para identificá-los, fornecer serviços apropriados, e atender da melhor forma às suas necessidades educacionais" (CLARK; ZIMMERMAN, 2004, p. 56).

Desse modo, como explica Guenther (2012), a identificação desses alunos na escola necessita de um tempo prolongado; e um processo de observação contínua, direta e sistemática, com base na sequência de acontecimentos presentes e nas diversas situações de ação, produção e desempenho em que o jovem se encontra envolvido. Para tanto, no contexto do ensino em artes visuais, se faz necessário que o professor da área - não só tenha conhecimento dos conteúdos e práticas inerentes ao exercício de sua função -, mas também adquira conhecimento adicional sobre esse público específico, para estar preparado a reconhecer os potenciais desses estudantes, promover alternativas adequadas de ensino, e encaminhá-los a um AEE.

Posto que, Clark e Zimmerman (2004) nos apresentem uma série de pesquisas e investigações em relação aos estudantes com talentos artísticos, muitas 


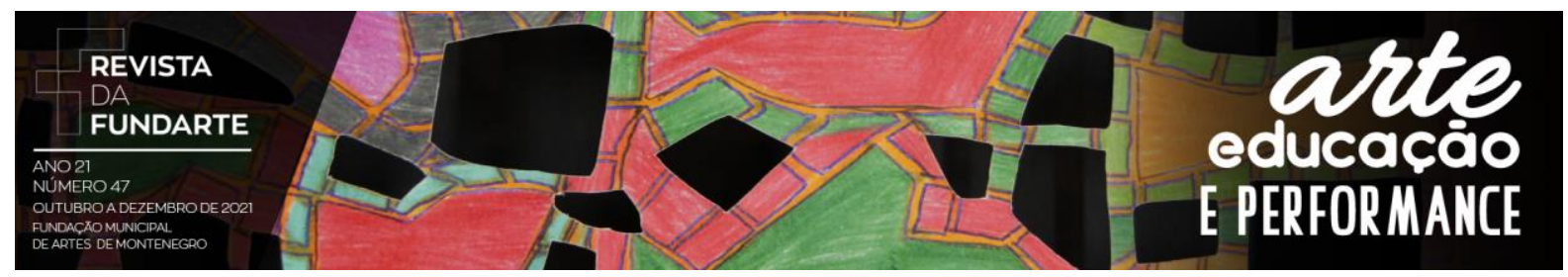

das quais os próprios autores conduziram, ambos observam que ainda há muita limitação para a identificação eficaz e eficiente desses estudantes, e que há muitas perguntas em aberto que precisam ser respondidas. Nesse sentido, eles advogam em relação à necessidade de mais investigações e pesquisas que tratem de questões de identificação do estudantes com potenciais artísticos, incluindo o uso e eficácia dos testes padronizados de $\mathrm{QI}$, desempenho e criatividade direcionados para esse público; os efeitos da formação, os da personalidade e os valores dos alunos em contextos específicos; estudos sobre idades apropriadas para procedimentos de identificação dos talentos artísticos, e o uso adequados em sistemas de múltiplos critérios de identificação. Nessa mesma linha, os autores pontuam também a necessidade de investigações e pesquisa sobre a:

[...] definição de talentos nas artes e a inclusão ou exclusão de cultura, características de estudantes, criatividade, habilidades de artes, habilidades cognitivas e afetivas, potenciais e/ou de desempenho, processos e/ou produtos, especializações de arte, e distribuição do talento artístico na escola e na população em geral. (CLARK; ZIMMERMAN, 1992, p. 29).

Mesmo com amplos estudos sobre as $\mathrm{AH} / \mathrm{SD}$, ainda há problemas referente ao alcance do conhecimento sobre essa parcela da população, refletidos nos preconceitos, na falta de formação do professorado e na insuficiência de atendimento. Quando essas questões são trazidas para o contexto das artes visuais, parece que esses problemas se agravam. Isso é tão verdade, que Clark e Zimmerman (2004) pontuam que mesmo que algumas questões sobre conceitos de superdotação e desenvolvimento do talento artístico sejam sanadas para fins de identificação, desenvolvimento de currículo e avaliação, ainda assim, estereótipos, concepções equivocadas, expectativas irreais, e mitos sobre os estudantes com talentos em artes visuais continuam a existir.

\section{Considerações finais}

Como já vimos anteriormente, as bases legais que instituem as normativas operacionais para o AEE na perspectiva da educação inclusiva, garantem 


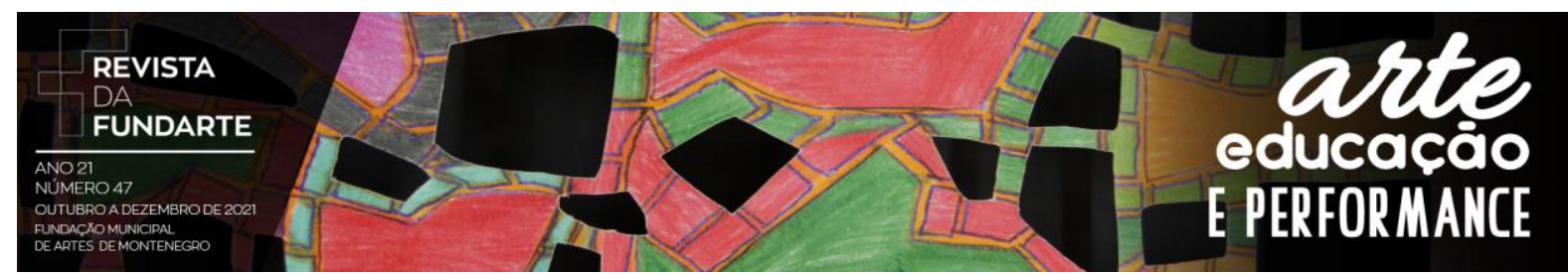

professores com formação inicial, habilitados para o exercício da docência e formação específica na educação especial, seja inicial ou continuada. Entre suas atribuições - além de orientar os demais professores da sala de aula regular - deve estabelecer articulação com esses professores, visando a plena integração do estudante nas classes comuns de ensino regular. No entanto, cabe também aos professores do ensino regular capacitação para a integração dos educandos da educação especial nas classes comuns.

Nesse sentido, fica evidente que a formação específica na educação especial é tão importante para aquele professor que atuará no $A E E$, quanto para aquele que exerce suas atribuições no ensino regular. Sem essa formação inicial e/ou continuada não tem como atender plenamente a demanda da inclusão escolar, principalmente, quando focamos nos alunos com AH/SD em artes visuais. Isso porque entendemos que muitos alunos com potenciais artísticos, dependem da observação qualificada e da sensibilidade apurada do professor de artes visuais atuante no ensino regular; para que seja reconhecido, indicado e encaminhado para um AEE. Assim, configura-se, a partir das diretrizes e procedimentos desenvolvidos neste apoio especializado a identificação, o cadastramento e $o$ atendimento a esses estudantes, proporcionando o enriquecimento e desenvolvimento de suas potencialidades artísticas.

Reconhecer talentos artísticos depende de um processo que deve ter respaldo em pesquisas e investigações, mas também necessita de políticas públicas que forneçam formação a todo o professorado das artes em todos os níveis e modalidades; a fim de proporcionar a todos os estudantes condições de descobrirem seus talentos, sejam nas artes ou em outra área do conhecimento humano. Desse modo, evidencia-se a necessidade da qualificação docente a respeito da temática, que promovam o conhecimento sobre as características dos estudantes, suas necessidades, suas habilidades e seus interesses específicos; de forma que possibilite a identificação dentro dos espaços educacionais, concretizando conjuntamente com o AEE - uma educação inclusiva.

\section{Referências:}




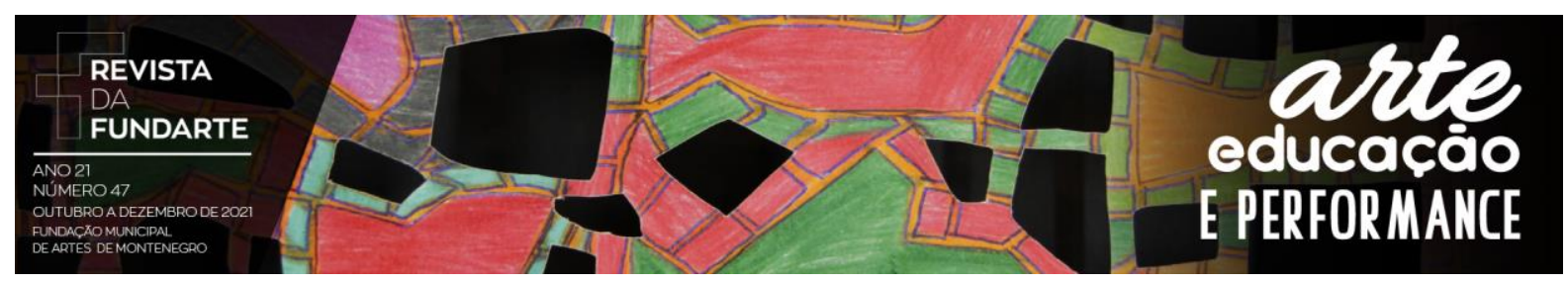

ALMEIDA, J. DO S. R. DE; MIGUEL, J. R. A Formação Docente para o Atendimento de Alunos com Altas Habilidades/Superdotação. ID on-line REVISTA DE PSICOLOGIA, v. 14, n. 51, p. 917-931, 30 jul. 2020. Disponível em: «< https://idonline.emnuvens.com.br/id/article/view/2642>>. Acesso em: 12 mai. 2021.

BRASIL. Resolução n.4, de 2 de outubro de 2009. Conselho Nacional de Educação/ Câmara de Educação Básica. Brasília. 2009, p. 3.

BRASIL. Decreto n. 7.611, 17 de novembro de 2011. Brasília: Casa Civil da Presidência da República. 2011 a.

BRASIL. Projeto de Lei do Senado (PLS) no 254, de 2011. Altera a Lei no 9.394, de 20 de dezembro de 1996 (Lei de Diretrizes e Bases da educação), para dispor sobre a identificação, o cadastramento e o atendimento aos alunos com altas habilidades ou superdotação na educação básica e superior. 2011 b, Sec. Senado.

BRASIL, Ministério da Educação. Política Nacional de Educação Especial na Perspectiva da Educação Inclusiva. Brasília: Secretaria da Educação Especial MEC/SEESP, 2008.

BRASIL, Ministério da Educação. Lei no 13.234, de 29 de dezembro de 2015. Brasília: MEC. 2015.

BRASIL, Lei no 9.394, de 20 de dezembro de 1996. Estabelece as diretrizes e bases da educação nacional. Diário Oficial da União, 23 dez. 1996, v. 134, n. 248, seção 1, p. 27833.

CUCHI, S. DE O. B.; PÉREZ, S. G. P. B. A arte e a pessoa com altas habilidades/superdotação. IV Congresso Internacional de Educação Inclusiva e V Jornada Chilena Brasileira de Educação Inclusiva. Anais...Campina Grande: Realize, $2020 \quad$ Disponível

em: <<https://www.editorarealize.com.br/index.php/artigo/visualizar/72307>>. Acesso em: 13 abr. 2020.

CLARK, G.; ZIMMERMAN, E. Issues and practices related to identification of gifted and talented students in the visual arts. Connecticut: National Research Center on the Gifted and Talented, 1992.

CLARK, G.; ZIMMERMAN, E. Teaching talented art students: principles and practices. NewYork, NY: Teachers College Press, 2004.

DELOU, C. M. C. Plano de atendimento educacional especializado integrado ao plano individual de ensino com vistas à aceleração de estudos: sugestão adaptada do modelo de Joseph Renzulli. In: VIRGOLIM, A. M. R.; KONKIEWITZ, E. C. (Eds.). 


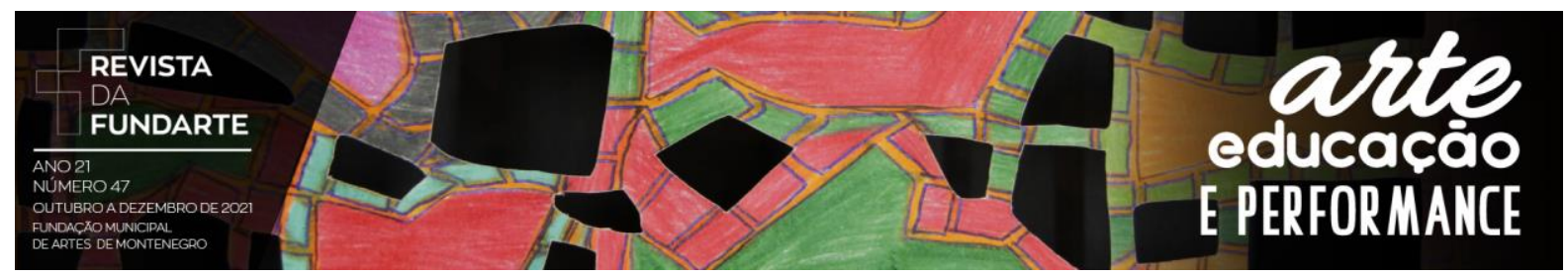

Altas habilidades/superdotação, inteligência e criatividade: Uma visão multidisciplinar. $1^{\text {a }}$ ed. Campinas, SP: Papirus Editora, 2018.

GUENTHER, Z. C. Quem são os alunos dotados? reconhecer a dotação e talento na escola. In: MOREIRA, L. C.; STOLTZ, T. (Eds.). Altas habilidades/superdotação, talento, dotação e educação. Curitiba: Juruá, 2012. p. 63-83.

MARQUES, D. M. C.; COSTA, M. DA P. R. DA (EDS.). Altas habilidades/superdotação: a intervenção educacional na precocidade a partir da teoria das inteligências múltiplas. São Carlos: Pedro \& João Editores, 2018.

NAKANO, T. DE C. Triagem de indicadores de altas habilidades/superdotação para professores: desenvolvimento de instrumental. Revista Diálogos e Perspectivas em Educação Especial, v. 7, n. 1, p. 71-68, 2020.

PEREIRA, V. L. P. Superdotação e currículo escolar: potenciais superiores e seus desafios da perspectiva da educação inclusiva. In: VIRGOLIM, A. M. R.; KONKIEWITZ, E. C. (Eds.). Altas habilidades/superdotação, inteligência e criatividade: Uma visão multidisciplinar. $1^{\text {a }}$ ed. Campinas, SP: Papirus Editora, 2018. p. 737-388.

PÉREZ, S. G. P. B. Altas habilidades/superdotação e a política educacional: uma cronologia de história de letras no papel e omissões na prática. In: VIRGOLIM, A. (Ed.). Altas Habilidades/superdotação: processos criativos, afetivos e desenvolvimento de potenciais. Curitiba: Juruá, 2018. p. 307-332.

RECH, A. J. D.; NEGRINI, T. Formação de professores e altas habilidades/superdotação: um caminho ainda em construção. Revista IberoAmericana de Estudos em Educação, v. 14, n. 2, p. 485-498, 2019.

SARZI, L. Z.; CAMARGO, R. G. Altas habilidades/superdotação: o que pensam os acadêmicos de cursos de licenciatura da universidade federal de Santa Catarina a respeito? Revista de Estudos e Pesquisas em Ensino de Geografia, v. 6, n. 10, p. 19-32, 2019.

SIGNORINI, L. C.; RONDINI, C. A. Avaliação psicológica e psicopedagógica junto à estudante com características de superdotação: estudo de caso. Revista Cocar, v. 15, n. 32, p. 1-21, 2021.

VIRGOLIM, A. M. R. Altas Habilidades/ Superdotação: Um diálogo pedagógico urgente. Curitiba: InterSaberes, 2019.

ZAIA, P.; NAKANO, T. DE C. Escala de identificação das altas habilidades/superdotação: evidências de validade de critério. Revista Iberoamericana de Diagnóstico y Evaluación - e Avaliação Psicológica. RIDEP, v. 2, n. 55, p. 31-41, 2020. 


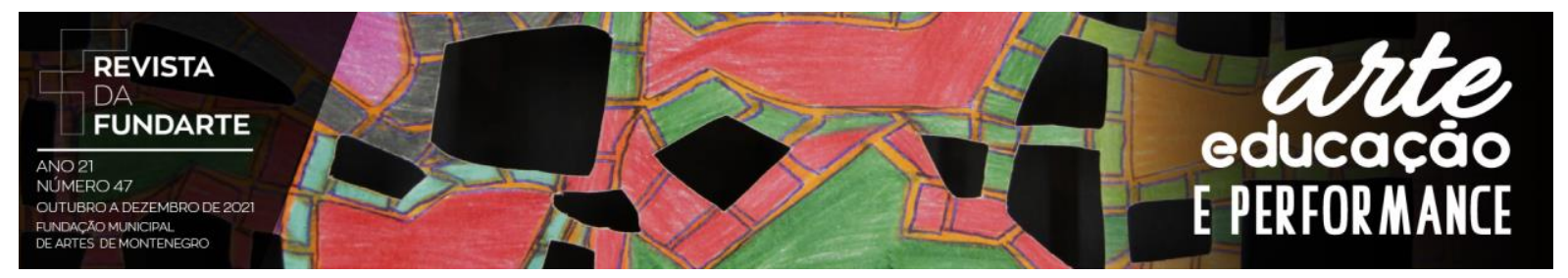

